\title{
21
}

\section{Inspiring Academics to Engage in Collegial Socialization: Pedagogical Provocations}

\author{
Heather Kanuka \& John Braga \\ University of Alberta
}

Academics who engage in collegial socialization can benefit in a variety of ways. The challenge, however, is creating a culture which inspires, within a voluntary model, academics to participate in such activities. Teaching development programs have tended to focus on teaching competencies and problem areas through offerings of workshops. It has been widely acknowledged that 'workshops don't work' when working with academics to enhance teaching development. Further, it is usually expected those academics in need of improving their teaching will attend the learning activities offered by teaching centers on their own time. However, expecting academics to attend professional development activities on their time is not a reasonable assumption. For a voluntary model of teaching enrichment to work, creating a culture to support teaching is vital. In this paper we describe an activity, which we named 'pedagogical provocations,' in an attempt to engage academics in collegial socialization about teaching and learning through provocative collegial dialogue.

\section{Introduction: Pedagogical Provocations}

T here is much talk about how the academy cares little about teaching (Christensen-Hughes \& Mighty, 2010). There is, however, evidence revealing that the majority of academics actually care deeply about teaching, would like to participate in learning opportunities, and want to be connected with colleagues in achieving excellence in teaching (Kanuka, Heller, Jugdev, \& West, 2008). This research is consistent with Palmer's (1999) assertion that collegial socialization is an essential aspect of teaching excellence. It is also consistent with Gosling's (2001) research, which revealed academics want to engage in sincere discussion about teaching; moreover, it is during these discussions that understandings about teaching and learning are developed. According to Palmer (1999), without collegial socialization a privatization or individualization of work evolves which "creates more than individual pain; it creates institutional incompetence as well. By privatizing teaching, we make it next to impossible for the academy to 
become more adept at reaching its mission" (p. 1). The outcome of privatized teaching is that the performance becomes more conservative and few stray from their comfort zones in regard to what is 'tried and true' - even when it does not work.

In an attempt to create collegial socialization, we developed 'pedagogical provocations.' Pedagogical provocations is a series of symposia aimed to foster collegial dialogue among faculty members through themed sessions, each of which has a provocative topic. The Centre for Teaching and Learning at the University of Alberta began the symposium series by celebrating instructors' commitments to teaching and learning, followed by facilitating collegial dialogue about provocative topics on teaching and learning across the University. Current and ongoing issues on several central committees inspired the topics for the symposia. Past topics have included, for example, learning spaces, graduate supervision, teaching-research nexus, student motivation and engagement, technology, citizenship, and how to use failure to move forward. Each session had a moderator and a panel that included a senior administrator (e.g., vice provost or associate vice president), faculty member, graduate student, and undergraduate student. The panel was comprised in this manner to ensure there were presentations from diverse perspectives. Each panel member was provided with a one- or two-page overview of the research on the topic and 3-5 questions of which they were asked to provide a 5-10 minute response. After the panel responded to the questions, the audience was then given an opportunity to present questions to the panel members. The symposia were held the third Thursday of every month. Between 20-40 faculty members attended every month.

Over several sessions we made an interesting observation: those attending the sessions were not the same each month; rather, those attending came based on their interest on the topic. Perhaps of even greater interest was the dynamic and engaging dialogue between and among the audience and panel that occurred with every issue. We believe the dynamic and engaging dialogue was due to the effectiveness of the moderator. Specifically, the moderator asked pointed and provocative questions about the issue, as well as ensured a safe space was provided for the participants (both the audience and panel member) so they could express their views in a manner that was open, honest and respectful. The result was collegial discussions across disciplines, which not only resulted in collegial socialization, but a sense of belongingness.

\section{A Sense of Belongingness}

There seems to be a widespread belief that the academy cares little about teaching (see for example, Christensen Hughes \& Mighty, 2010). Such explanations include time restraints for teaching and research, lack of collegial relationships, little or no feedback, lack of recognition and/or reward, unrealistic expectations, and insufficient resources (Sorcinelli, 1994). Austin (2002; see also Greyling \& Rhodes, 2004) depicts a picture of academic work where faculty members must confront increasingly complex changes that have a tremendous impact on the work and lives of those entering the academy. Examples of increasing pressures include:

Public scepticism and demands for accountability, fiscal constraint, the rise of information society and new technologies, the increasing diversity of students, new educational institutions, the increasing emphasis on learning over teaching, the emergence of postmodern ways of knowing, and dramatic shifts in the nature of faculty appointments. (Austin, 2002, p. 123)

As importantly, faculty have also expressed feelings of disconnectedness and loneliness (Cox, 1997; Johnsrud, 1994), as well as those of being perceived as a neglected resource, often detached from other departmental colleagues (Boice, 1992). Research into what new faculty members really want has revealed that a sense of community is of primary importance. Humans, as Maslow (1943) has argued, need to have a sense of belongingness, commonly referred to as community. Rice, Sorcinelli, and Austin (2000) have observed that: 
Many early-career faculty and graduate students who aspire to join the faculty hold dear a vision of a "culture of collegiality"...they want to pursue their work in communities where collaboration is respected and encouraged, where friendships develop between colleagues within and across departments, and where there is time and opportunity for interaction to talk about ideas, one's work, and the institution. (p. 13)

Prior research has illustrated a desire by faculty to be part of a community and have a sense of belongingness as they enter into academe (Kanuka \& Marini, 2006). Following is a quote from this study:

When I was offered, and accepted, this position my family and I were very excited about moving here. I was really looking forward to working with other academics in my field and making new friends. ... I have made no new friends. Everyone does their own thing in my faculty, which is hard for me because I am a very social person. I am wondering if I have made a serious blunder in my choice of career.

Boyle (1996) has maintained further those institution-wide programs that provide support and resources (such as, for example, collegial dialogues) are required for academics to achieve a sense of belonging. A sense of belonging, in turn, is required for academics to research their full potential, or as Maslow (1943) argued, 'self-actualize.' CochranSmith (2004) has, similarly, argued that we need to move beyond solitary reflective practice and engage in such activities as collegial dialogue about critical issues. With ongoing dialogue, whereby the practices and issues are examined by many, the results are more of a 'super-reflection' - which helps to improve teaching and reshape the university culture and practices. Clearly, fostering collegial dialogue is important for a variety of reasons.

\section{Collegial Dialogue}

Fostering a collegial dialogue among faculty members is a way in which the aforementioned perceptions of neglect and detachment may be addressed. The perceptions of neglect and detachment are supported by Schoenfeld and Magnan (1992), who maintain that many university departments apply a form of Social Darwinism, that is "Let's throw the new kids off the end of the pier and see whether they can swim or not. We didn't get any survival advice, why should they?" [sic] (p. 7). On the upside, research by Fouche (2006) showed that feelings of isolation can be significantly decreased when there is regular contact and collaboration amongst colleagues. The most effective contact activities are those that revolve around the provision of regular training and continuous administrative support. Elsewhere, Wheeler (2004; see also Lockwood \& Latchem 2004; Schrum \& Ohler 2005) noted that, while continuous learning opportunities provide teaching staff in institutions of higher education with essential information on new methods, technologies, and applications, it also provides opportunities to have contact with, and collaboration among, colleagues in ways that support identification with the institution while at the same time defraying feelings of isolation. Hence, there is sufficient evidence to suggest the provision of continuous learning opportunities can provide collegial socialisation and institutional identification.

More recently, results from prior research show that most academics do, in fact, care deeply about their work, would like to participate in continuous learning opportunities, and want to be connected with likeminded colleagues in the development of innovative interactions that support excellence in instruction and the scholarship of teaching (Kanuka, Jugdev \& Heller, 2008). Prior research has shown that if left unattended, academics experience a sense of isolation that eventually progresses toward exasperation, disillusionment, and eventual alienation (Eib \& Miller, 2006; Smith \& Smith, 1993). 


\section{Précis}

Even without the research data, most of us at an intuitive level would not disagree there are benefits of collegial socialisation. The challenge is creating a culture which inspires, within a voluntary model, academics to participate in such activities. Teaching development programs have tended to focus on teaching competencies and problem areas through offerings of workshops. It is usually expected those academics in need of improving their teaching will attend the learning activities offered by teaching centres on their own time. However, as Kinuthia (2005) points out, "expecting faculty to attend training on their time means that only those who are truly motivated and have an interest will pursue the training" (p. 198). For a voluntary model of teaching enrichment to work, creating a culture to support teaching is vital (Harrison, 2002). However, many higher education institutions have created a culture that supports research and publishing, resulting in uninspiring participation rates for teaching growth activities.

The context of a given institution will shape the effort to create an environment where academics are motivated to participate in dialogues related to teaching. These discussions, especially on provocative topics, are best served through connecting with all levels of the campuswide community (senior administrators, faculty members, graduate students, and undergraduate students) and recognizing the diverse roles these stakeholders fulfill in the conversation. Yet the task of inspiring academics to join in a collegial dialogue forum about teaching and learning is one that is challenging for institutions of higher education; it requires creative responses. Despite this, collegial inquiring into our teaching is an activity that enriches the academic community.

In closing, research is needed to determine whether collegial dialogue can create a culture that supports excellence in teaching, while fostering connectedness between and among faculty members, and the institution - and whether this is, as we advocate, vital to continuous innovation and improvement in teaching.

\section{References}

Austin, A.E. (2002). Creating a bridge to the future: Preparing the new faculty to face changing expectations in a shifting context. The Review of Higher Education, 26(2), 119-144.

Boice, R. (1992). Lessons learned about mentoring. New directions for teaching and learning, 50. San Francisco: Jossey-Bass.

Boyle, R. (1996). First-order principles for college teachers: Ten basic ways to improve the teaching process. Bolton, MA: Anker Publishing.

Christensen Hughes, J. \& Mighty, J. (2010). Taking stock: Research on teaching and learning in higher education. Kingston. ON: McGillQueen's University Press.

Cochran-Smith, M. (2004). Walking the road: Race, diversity and social justice in teacher education. NY: Teachers College Press.

Cox, M.D. (1997). Long-term patterns in a mentoring program for junior faculty: Recommendations for practice. To Improve the Academy, 16, 225-268.

Eib, B.J. \& Miller, P. (2006). Faculty development as community building. International Review of Research in Open and Distance Learning, 7(2).

Fouche, I. (2006). A multi-island situation without the ocean: Tutor's perceptions about working in isolation from colleagues. International review of Research in Open and Distance Learning, $7(2)$.

Gosling, D. (2001). What educational developments unit do - Five years on. International Journal for Academic Development, 6(1), 74-92.

Greyling, L. \& Rhodes, B.G. (2002). Promoting high quality performance through mentoring: A programme for higher education. Proceedings 
in Improving University Teaching, Bern, Switzerland.

Harrison, J.E. (2002). The quality of university teaching: Faculty performance and accountability. A literature review. Canadian Society for the Study of Higher Education, 21, 1-18.

Johnsrud, L.K. (1994). Enabling the success of junior faculty women through mentoring. In M.A. Wunsch (Ed.), Mentoring revisited: Making an impact on individuals and institutions (pp. 53-63). San Francisco: Jossey-Bass.

Kanuka, H. \& Marini, A. (2005). Empowering untenured faculty through mosaic mentoring. Canadian Journal of University Continuing Education, 30(2), 11-38.

Kanuka, H., Jugdev, K., \& Heller, B. (2008). The Factor Structure of Faculty Development Needs for Net-based Distance EducationPractitioners. International Journal for Academic Development, 13(2), 129-139

Kanuka, H., Heller, B., Jugdev, K., \& West, D. (2008). The rise of the teleworker: False promises and responsive solutions. Higher Education, 56(2), 149-165.

Kinuthia, W. (2005). Planning faculty development for successful implementation of web-based instruction. Campus-Wide Information Systems, 22(4), 189-200.

Lockwood, F. \& Latchem, C. (2004). Staff development needs and provision in commonwealth countries: Findings from a commonwealth of learning training impact study. Distance Education, 25(2), 9-12.

Maslow, A.H. (1943). A theory of human motivation. Psychological Review, 50(4), 370-396.

Palmer, P. (1999). The courage to teach. San Francisco: Jossey-Bass.
Rice, R.E., Sorcinelli, M.D., \& Austin, A.E. (2000). Heeding new voices. Academic careers for a new generation. Washington, DC: American Association for Higher Education.

Schoenfeld, A.C., \& Magnan, R. (1992). Mentor in a manual. Climbing the academic ladder to tenure. Madison, WI: Atwood.

Schrum, L. \& Ohler, J. (2005). Distance education at UAS. A case study. Journal of Distance Education, 20(1), 60-83.

Sorcinelli, M. D. (1994). Effective approaches to new faculty development. Journal of Counseling \& Development, 72, 474-479.

Smith, B. \& Smith, M. (1993). Revitalizing senior faculty through statewide efforts. In $\mathrm{M}$. Finkelstein \& M. LaCelle-Peterson (Eds.), Developing senior faculty as teachers. San Francisco: Jossey-Bass.

Wheeler, S. (2004). Five smooth stones: Fighting for the survival of higher education. Distance Learning, 1(3), 11-17.

\section{Biographies}

Heather Kanuka is Academic Director for the Centre for Teaching and Learning and Professor in Educational Policy Studies, Faculty of Education, University of Alberta. Heather's research interests include philosophies of teaching and technology, instructional designer and academic development.

John Braga is a graduate student in Educational Policy Studies, Faculty of Education, University of Alberta. John's research interests include scientific reasoning and teaching and learning in higher education. 